\title{
Driven evidence-based nursing to diagnostic accuracy of water swallow test for stroke patients with dysphagia
}

\author{
Ching-Hui Chuang* \\ Department of Rehabilitation, Kaohsiung Chang Gung Memorial Hospital, Taiwan
}

\begin{abstract}
Background: The ability of nursing staff to determine stroke deglutition disorders is important in care of stroke patients.

Purpose: This study aimed to increase diagnostic accuracy of stroke deglutition disorders among nursing staff in stroke care.

Method: By comprehensive determination of the most accurate water volume for the diagnosis of stroke deglutition disorders using evidence-based meta-analysis.

Results: The diagnostic accuracy of stroke deglutition disorders made by nursing staff was increased from $4.75 \%$ to $100 \%$, and the incidence of aspiration pneumonia in patients with stroke was decreased from $2.59 \%$ to $1.36 \%$.

Conclusion: By applying meta-analysis of diagnostic tests to clinical practice, nursing staff can increase diagnostic accuracy of stroke deglutition disorders.
\end{abstract}

\section{Background}

\section{Quality and Quantity of PICO (target determination)}

Clearly describe clinical issues of target population: Swallowing is one of the most important functions in humans. The loss of swallowing function causes an inability to maintain the energy levels required for living. Previous studies indicate that approximately $37 \%-45 \%$ of stroke patients suffer from stroke deglutition disorders [1], and their chewing difficulties or stroke deglutition disorders may result in complications such as aspiration pneumonia, dystrophy, dehydration and prolonged hospitalization. In addition, aspiration pneumonia has become the leading cause of death in patients with stroke [2]. To reduce the risk of aspiration pneumonia, swallowing evaluation becomes critical in the care of stroke patients [3]. The water swallow test is one of the tools adopted in swallowing evaluation. Healthcare staff can apply water swallow tests to evaluate the risks of aspiration pneumonia in patients with stroke deglutition disorders [4].

Clearly describe primary/other interventions or exposure factors: The swallowing evaluations for patients with stroke deglutition disorders include swallowing evaluation, fiber optic endoscopic evaluation of swallowing (FEES) and video fluoroscopic swallowing exam (VFSE). However, FEES and VFSE were considered inconvenient and dangerous to acute stroke patients [5]. Originally VFSE was the gold standard examination for diagnosis of stroke deglutition disorders, but considering many limitations upon application, other more available swallowing evaluations such as the water swallow test [6] were subsequently developed.

Accurately determine index factors of study importance: The index factors regarding the importance of study results are as follows:

1. Accuracy rate of water swallow tests in patients with stroke deglutition disorders.

2. Completion rate of water swallow test checklist in patients with stroke deglutition disorders.

3. Incidence of aspiration pneumonia in patients with stroke deglutition disorders.

\section{Purpose}

Due to the lack of accuracy and knowledge of water swallow tests in caring for patients with stroke deglutition disorders, this study aimed to evaluate the accuracy of water swallow tests in patients with stroke deglutition disorders using meta-analysis. By comparing diagnostic accuracy before and after applying "water swallow tests" in patients with stroke deglutition disorders, clinical healthcare staff will be able to determine high-risk, and provide substantial suggestions to clinical caring practice for reference. Furthermore, the results can be used in early prevention of aspiration pneumonia in patients with stroke deglutition disorders, so these patients can receive prompt and safe care.

\section{Methods}

\section{Literature review}

This study investigated the importance of the water swallow test on diagnostic accuracy of stroke deglutition disorders in patients with

Correspondence to: Ching-Hui Chuang, MSN, RN, Head Nurse, Department of Rehabilitation, Kaohsiung Chang Gung Memorial Hospital, and Assistant Professor, Department of Nursing, Chang Gung University of Science and Technology, No.123, Dapi Rd., Niaosong Dist., Kaohsiung City 83301, Taiwan, ROC, Tel: +8 867731-7123; +8 867731-2965; E-mail: chinhui@cgmh.org.tw

Key words: evidence-based nursing, meta-analysis of diagnostic test, stroke, diagnostic accuracy of stroke deglutition disorders

Received: January 03, 2016; Accepted: January 19, 2016; Published: January 22 2016 
stroke using systemic retrospective analysis and meta-analysis. English databases such as Cochrane Library, MEDLINE, CINAHL, ProQuest Dissertations and Theses (PQDT), PubMed, PsycInfo and AgeLine as well as Chinese databases such as CETD were used for literature searching. The publication dates of studies in individual databases were between 1990 and December, 2014, and search keywords were focusing on studies with Population (P): "patients with Stroke Deglutition Disorders [MeSH]", Intervention (I): "water swallow test [Title/ Abstract]", Comparison (C): "Fiber-optic Endoscopic Examination (FEES) and Video-Fluoroscopic swallowing study (VFSE)", Outcome (O): "sensitivity and specificity", and Style (S): "diagnostic research". The inclusion criteria for literature assessment and selection were as follows: articles with publication dates between 1990 and January 2013; patients with Stroke Deglutition Disorders; no specific sex or species limitations; using water swallow test, FEES or VFSE as interventions; and using sensitivity and specificity as index factors. The exclusion criteria consisted of non-Chinese or non-English articles; involving two or more interventions in which individual importance of monotherapy couldn't be determined; review articles or retrospective articles. In addition, duplicate articles among selected literature were only counted once. A total of 171 articles from nine Chinese or English databases were screened, and only 12 articles related to study objectives were selected in the end [7-16] (Figure 1).

\section{Accurately use QUADAS}

The scoring system of the Cochrane handbook Quality Assessment of Diagnostic Accuracy Studies (QUADAS) was applicable for diagnostic studies. There were in total 11 questions, and the respondents could choose "Yes, No, Unclear or Not Applicable" as their answers. "Yes" answers got 1 point, other answers received zero points. Two different reviewers who had received evidence-based training critically and independently reviewed each selected article. Comments from a third reviewer were sought to reach a consensus while different opinions from two reviewers were received (Figures 2 and 3).

\section{Accurately and critically assess "importance"}

This study used the statistical analysis software Stata version 13.1 to analyze the accuracy of the water swallow test. The index variables were sensitivity, specificity and diagnostic odds ratio. A bivariate random effect model was applied in this study. A forest plot was used to present effect size estimates of sensitivity and specificity; values of $0.2,0.5,0.8$ in $95 \%$ confidence interval ( $95 \% \mathrm{CI}$ ) were used to indicate low, moderate or high effect size; and a Funnel plot was applied to show publication bias [17]. The regression analysis showed no significant publication bias between studies ( $p=.08$, Figure 4 ). Therefore, publication bias did not have impact on the results of this meta-analysis.

One hundred and seventy-one articles from 9 Chinese or English databases were screened, and 12 articles that were related to study objectives were selected in the end. The publication dates of these literatures were between 1990 and December, 2014. Total subjects recruited in those 12 articles were 1010 people. The sensitivity results of the meta-analysis showed that $\mathrm{Q}=97.92 ; p=.00 ; I 2=83.66 \%$, and the specificity results displayed that $\mathrm{Q}=137.45 ; p=.00 ; I 2=88.36 \%$. Hence, heterogeneities between 12 articles were noted (Figure 5). The source of potential heterogeneity was derived from the volumes used in of the water swallow test using univariate meta-regression analysis. The

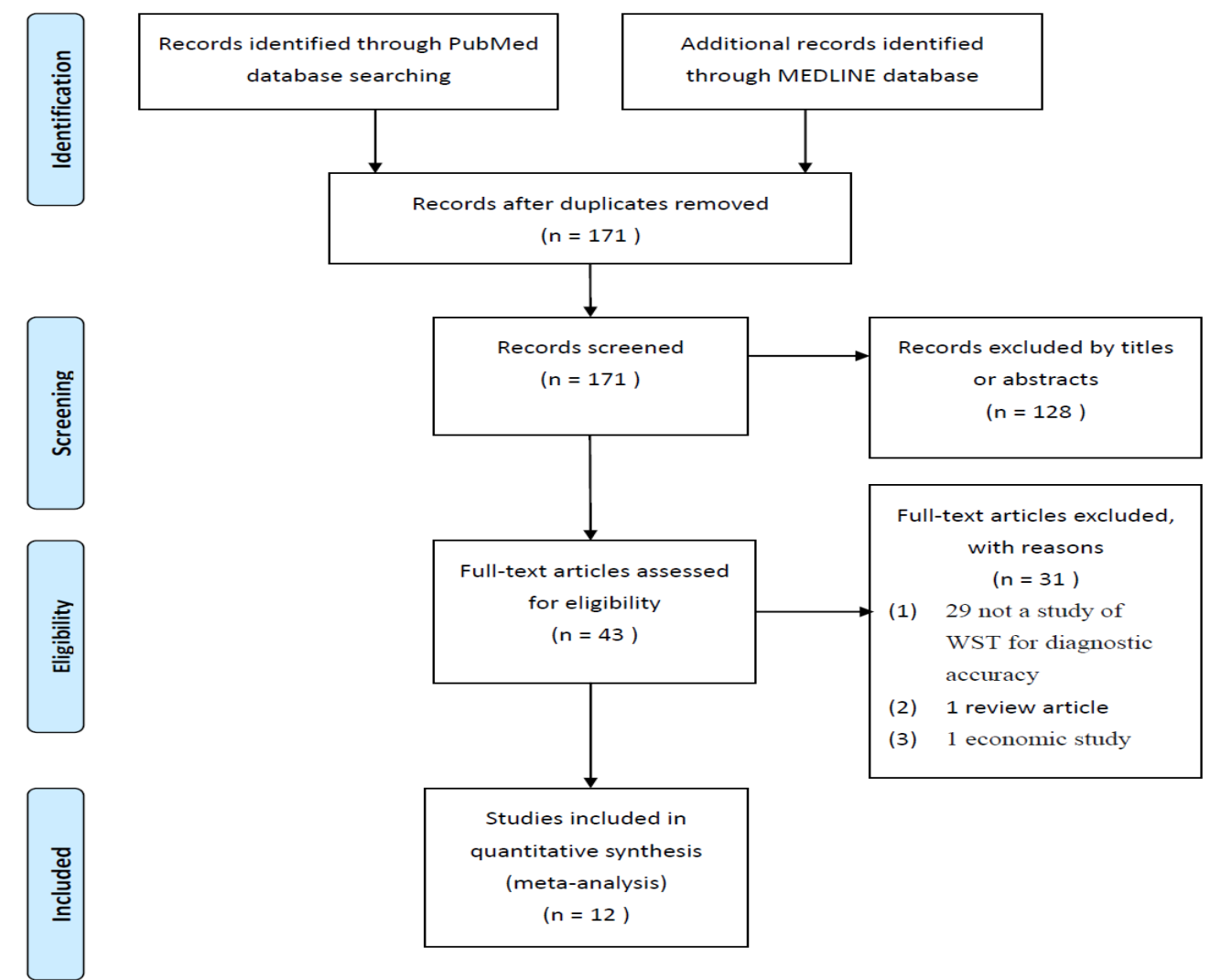

Figure 1. Flowchart of literature selection. 


\begin{tabular}{|c|c|c|c|c|c|c|c|c|c|c|c|c|c|}
\hline & $\underset{\infty}{\mathbb{\infty}}$ & 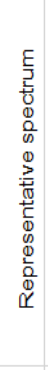 & 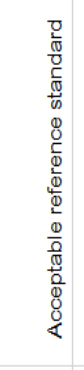 & 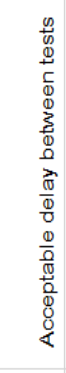 & 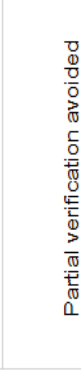 & 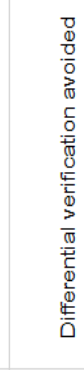 & 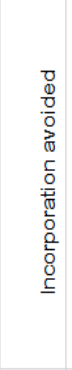 & 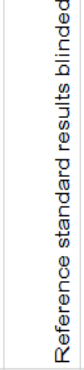 & 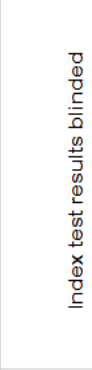 & & & 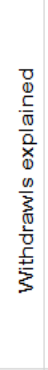 & \\
\hline Somasundaram et al. 2014 & $2014 y$ & & yes & yes & yes & yes & yes & unclear & unclear & yes & yes & & yes \\
\hline Osawa et al. $2013^{\mathrm{a}}$ & $2013 \mathrm{y}$ & & yes & yes & yes & yes & no & unclear & unclear & yes & yes & & yes \\
\hline Osawa et al. $2013^{\mathrm{b}}$ & $2013 \mathrm{y}$ & & yes & yes & yes & yes & yes & unclear & unclear & yes & yes & & yes \\
\hline Zhou et al. 2011 & $2011 y$ & & yes & yes & yes & yes & yes & yes & yes & yes & yes & & yes \\
\hline Kopey et al. 2010 & $2010 y$ & & unclear y & yes & yes & yes & yes & unclear & unclear & yes & yes & & yes \\
\hline Nishiwaki et al. 2005 & $2005 y$ & & yes & yes & yes & yes & yes & unclear & unclear & yes & yes & & yes \\
\hline Chong et al. 2003 & $2003 y$ & & yes & yes & yes & yes & yes & yes & yes & yes & yes & & yes \\
\hline Lim et al. 2001 & $2001 y$ & & yes & yes & yes & yes & yes & yes & yes & yes & yes & & yes \\
\hline Mann et al. 2001 & $2001 y$ & & yes & no & no & yes & yes & yes & yes & yes & yes & & yes \\
\hline Daniels et al. 1997 & $1997 \mathrm{y}$ & & yes & yes & yes & yes & yes & unclear & unclear & yes & yes & & yes \\
\hline Kidd et al. 1993 & $1993 \mathrm{y}$ & & yes & yes & yes & yes & yes & unclear & unclear & yes & yes & & yes \\
\hline DePippo et al. 1992 & $1992 y$ & & yes & unclea & ayes & yes & yes & unclear & unclear & yes & yes & & yes \\
\hline
\end{tabular}

Figure 2. QUADAS.

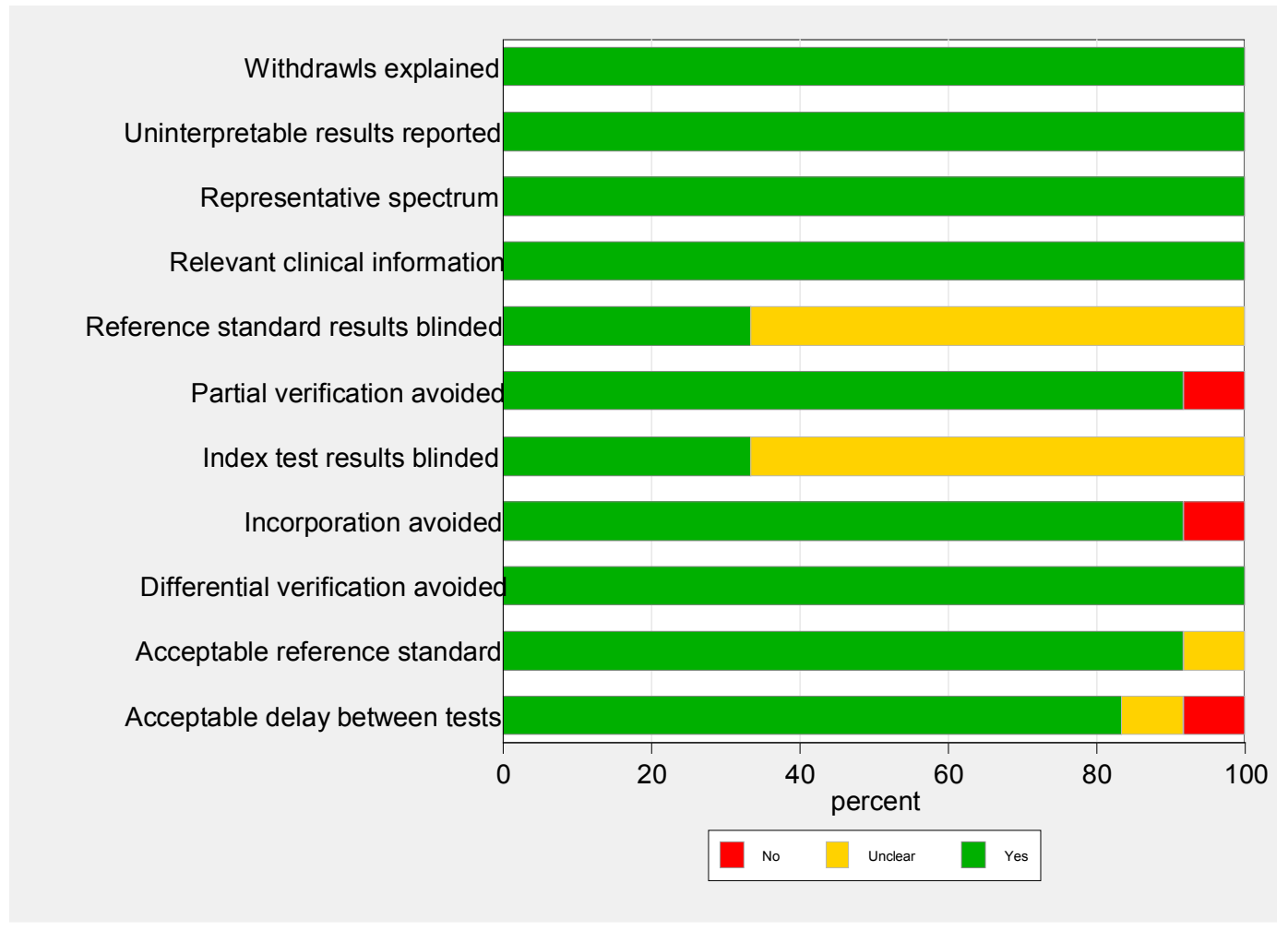

Figure 3. Quality of literature.

results showed that the volumes of used in the water swallow test may result in sensitivity and specificity heterogeneities. Osawa et al. $[18,19]$ used 5 different volumes for water swallow tests (i.e. $60 \mathrm{ml}, 30 \mathrm{ml}, 10$ $\mathrm{ml}, 5 \mathrm{ml}$, and $3 \mathrm{ml}$, respectively). Hence, there were 16 water swallow tests within 12 selected articles, and each study consisted of different thresholds. Three of these studies used $70-90 \mathrm{ml}$ as their water swallow test volume, five studies used $50-60 \mathrm{ml}$ as their water swallow test volume, and eight studies used $30 \mathrm{ml}$ or less as their water swallow test volume. The studies were conducted in Asia, Europe and America, in six countries. Target subjects were focused on patients with acute, subacute or chronic stroke. The pooled sensitivity of 15 water swallow tests was $0.62(95 \% \mathrm{CI}=0.52-0.70)$ while the pooled specificity was $0.81(95 \%$ $\mathrm{CI}=0.73-0.88)$, and the diagnostic odds ratio (DOR) was $6.96(95 \%$ $\mathrm{CI}=4.90-8.91)$. The analysis of baseline hierarchical summary receiver operating characteristic curve (HSROC) is shown in Figure 6, with the area under the curve $(\mathrm{AUC})=0.77(0.73-0.81)$. 


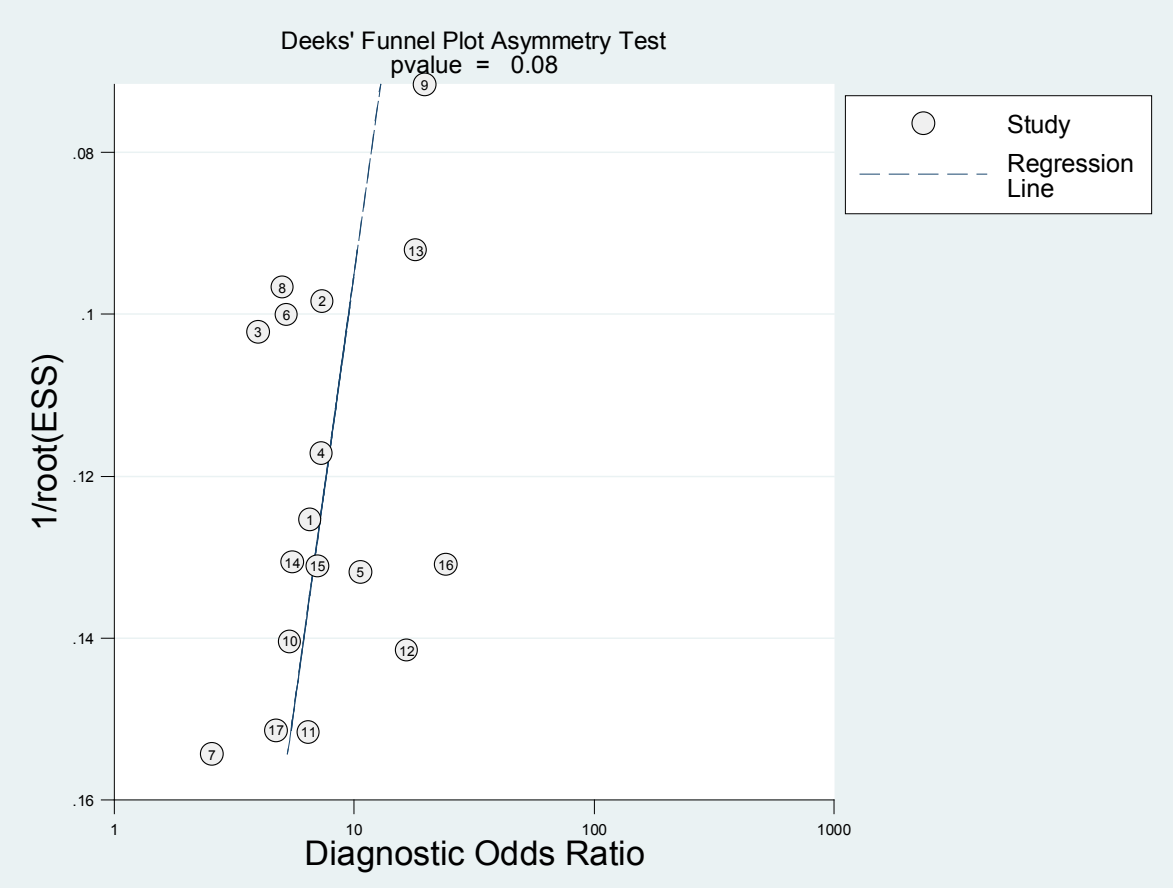

Figure 4. Publication bias.

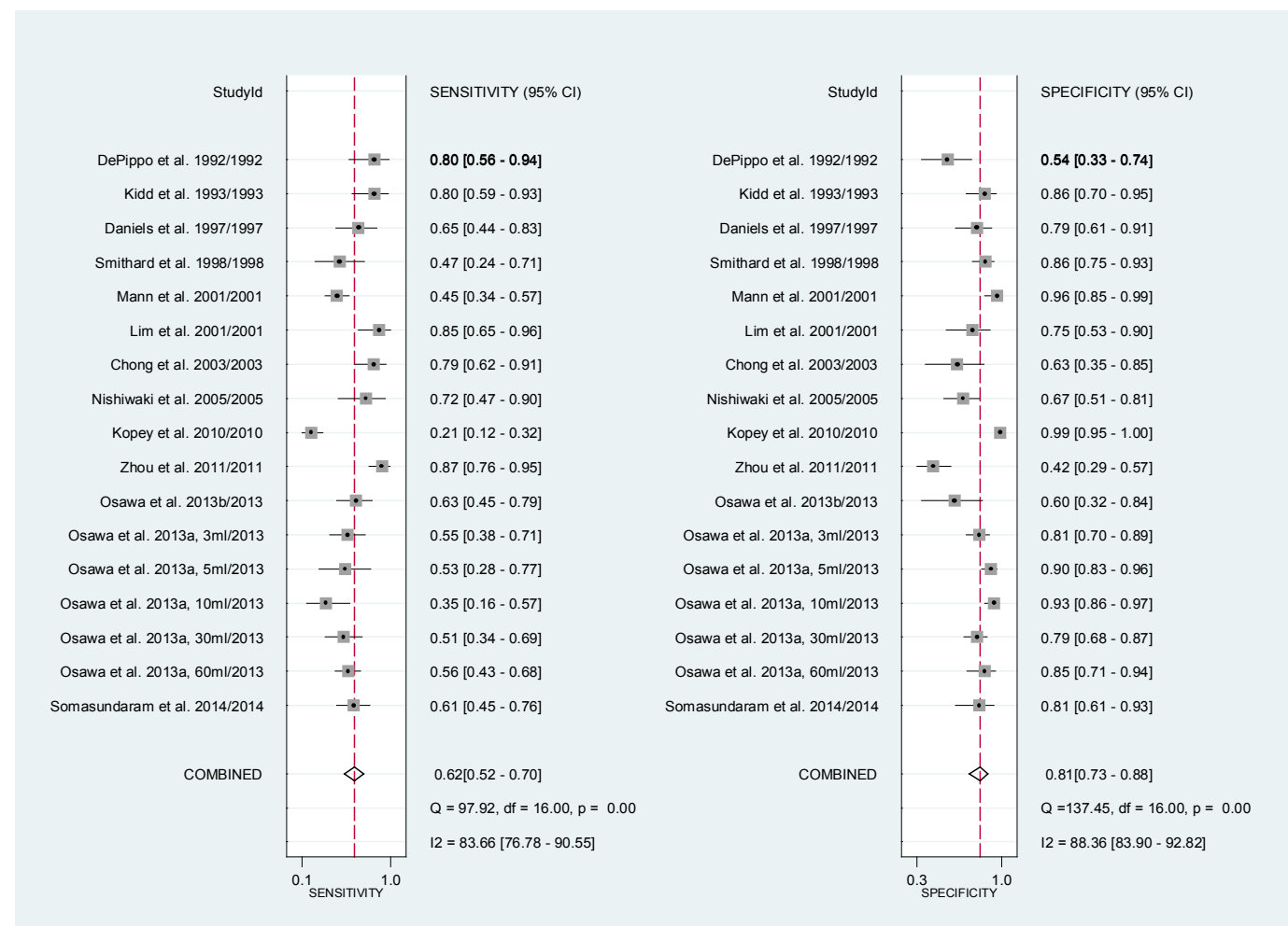

Figure 5. Meta-analysis Diagram for Study Heterogeneity. A) Test for Sensitivity Heterogeneity: $Q=97.92, d f=16(p=.00) ; I^{2}=83.66 \%$ B) Test for Specificity Heterogeneity: $Q=137.45$, $d f=16(p=.00) ; I^{2}=88.36 \%$.

Meta-regression revealed that the sensitivity of water swallow tests with $\geqq 50 \mathrm{ml}$ volume was significantly higher than the test with $<50 \mathrm{ml}$ volume ( $p=.002)$ (Appendix I).

\section{Sensitivity analysis}

The results of anomaly detection model analysis, including Cook's distance and scatter plot, are shown in Figure 7. We found that one 
of the selected studies deviated from the research group. To prevent model mismatching and inaccurate estimations of study variables, we decided to delete the study results of this deviated study. After recalculation, we found that the sensitivity became 0.65 ( $95 \% \mathrm{CI}=0.57$ $0.73)$ and the pooled specificity became 0.78 ( $95 \% \mathrm{CI}=0.70-0.85)$, while the DOR was $6.56(95 \% \mathrm{CI}=4.89-8.80)$. The AUC of the HSROC was changed to $0.77(0.73-0.81)$.

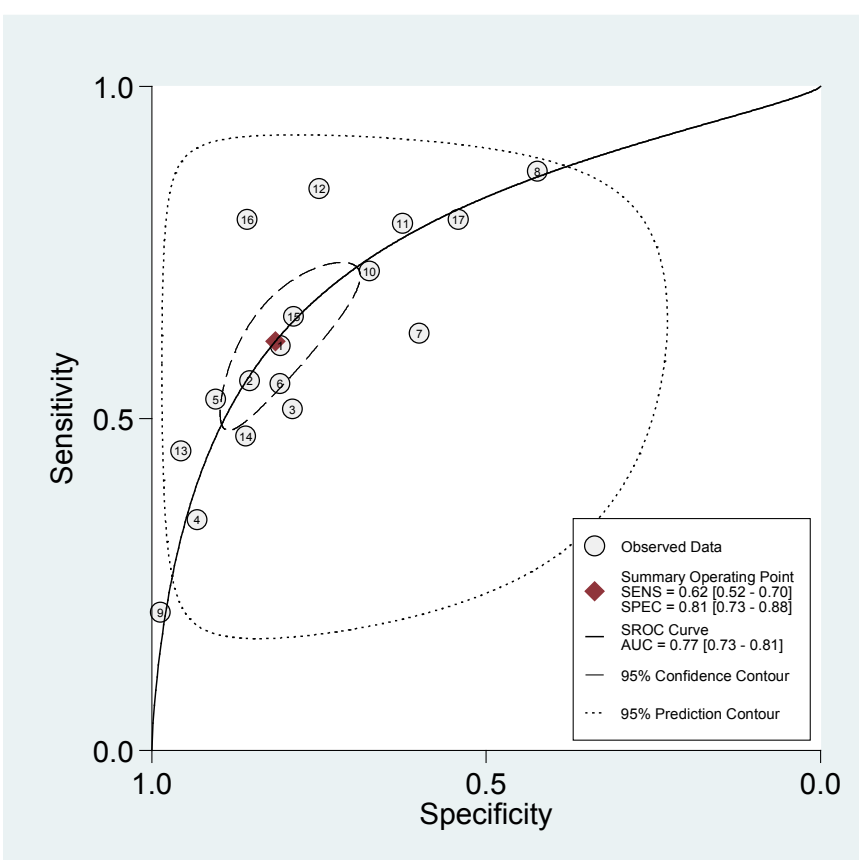

Figure 6. Hierarchical summary receiver operating characteristic curve (HSROC).

\section{Accurately determine the evidence and integrate knowledge}

According to the evidence of the GRADE guidelines written in the handbook for DTA reviews, which was published by the Cochrane diagnostic test accuracy working group, the results of this diagnostic meta-analysis was strong recommendation, high quality evidence. In summary, we conclude that the specificities of water swallow tests with either $\geqq 50 \mathrm{ml}$ or $<50 \mathrm{ml}$ volumes were similar. However, the sensitivities were different, i.e. water swallow tests using $\geqq 50 \mathrm{ml}$ volume had significantly higher sensitivity.

\section{From evidence to application}

\section{Find out the differences between knowledge and actions (7A)}

The water swallow test has had difficulty in being considered as an effective swallow test for a long time. According to the study results published by Maeshima et al. [20] and Tohara et al. [21], excessive water volume used in a water swallow test may result in aspiration pneumonia in stroke patients. Our study results show that water swallow tests using $\geqq 50 \mathrm{ml}$ volumes could lead to the most sensitive results in stroke patients. Meanwhile, we also found that water swallow tests using less than $50 \mathrm{ml}$ volume presented lower sensitivity and moderate specificity, which consequently led to more false negative results.

There have been several articles published investigating the accuracy of water swallow tests. However, the evidence level of the study results couldn't be upgraded due to the lack of meta-analysis. This study conducted a model prediction procedure such as sensitivity analysis prior to the meta-analysis to improve the accuracy of the water swallow test in the results of meta-analysis. We also used graded guidelines proposed by Deeks [22], Liberati et al. [23] and Whiting et al. [24]
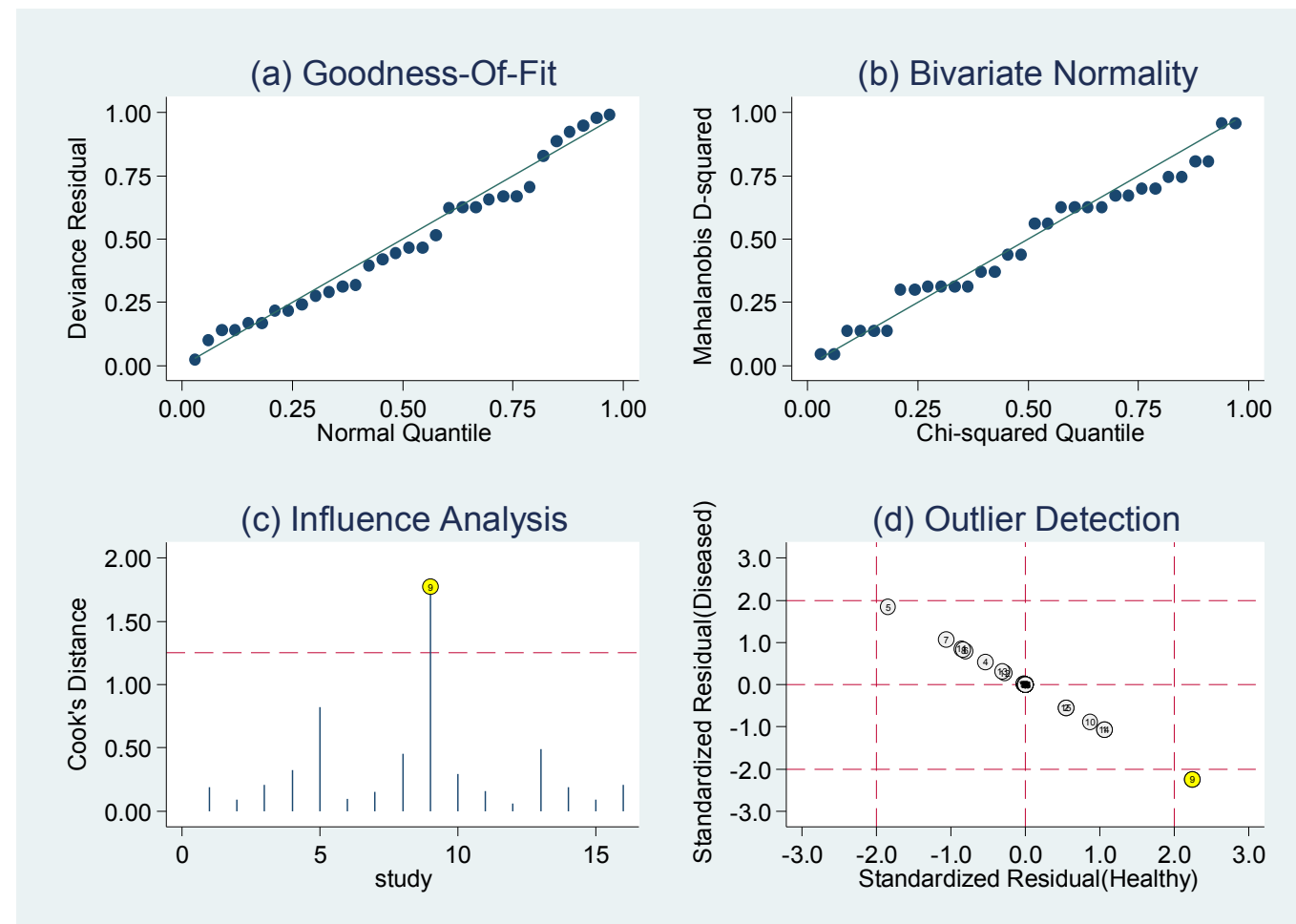

Figure 7. Model analysis of Cook's distance and scatter plot. 
in our meta-analysis, including a bivariate random effect model and HSROC, to carefully analyze our data. In conclusion, we recommend a water swallow test using $\geqq 50 \mathrm{ml}$ volume in stroke deglutition disorders evaluation.

\section{Importance evaluation}

Through conducting a comprehensive diagnosis of stroke deglutition disorders, the diagnostic results reminded us of the risks of aspiration pneumonia. Therefore, early intervention of swallowing therapy performed by a speech therapist may reduce the incidence of aspiration pneumonia in stroke patients, i.e. the incidence before and after the implementation of a water swallow test promotion program was diminished from $2.59 \%$ to $1.36 \%$, while the OR was $0.48(95 \%$ $\mathrm{CI}=0.28-0.8, P=.002)$.

\section{Conclusion}

This study aimed to investigate the diagnostic accuracy of the water swallow test in patients with stroke deglutition disorders. It was a systemic retrospective review. After data collection, screening, encoding, registration and analysis, the study results showed that a water swallow test using $\geqq 50 \mathrm{ml}$ volume results in higher study sensitivity. In subsequent follow-up studies, we used $100 \mathrm{ml}$ in the water swallow test. The results showed that the accuracy and completion rates of water swallow test could reach $100 \%$ once the consistency training of the water swallow test was completed. Moreover, the incidence of aspiration pneumonia and the medical expenses for subsequent treatment were effectively reduced. In conclusion, application of accessible water swallow tests and establishment of related healthcare knowledge should be done without delay. Studies regarding the safety of water swallow tests should be pursued in the future. Hopefully by doing so, patients with stroke deglutition disorders can be treated promptly and effectively, and the professional image as well as ability of healthcare staff can also be boosted.

\section{References}

1. Martino R, Foley N, Bhogal S, Diamant N, Speechley M, et al. (2005) Dysphagia after stroke: incidence, diagnosis, and pulmonary complications. Stroke 36: 2756-2763. [Crossref]

2. Brogan E, Langdon C, Brookes K, Budgeon C, Blacker D (2014) Dysphagia and factors associated with respiratory infections in the first week post stroke. Neuroepidemiology 43: 140-144.[Crossref]

3. ASGE Standards of Practice Committee, Pasha SF, Acosta RD, Chandrasekhara V, Chathadi KV, et al. (2014) The role of endoscopy in the evaluation and management of dysphagia. GastrointestEndosc 79: 191-201.[Crossref]

4. Ho YH, Liu HY, Huang ST (2014) [The prevalence and signs of Dysphagia among stroke patients in rehabilitation units]. Hu Li ZaZhi 61: 54-62. [Crossref]

5. Warnecke T, Teismann I, Meimann W, Olenberg S, Zimmermann J, et al. (2008) Assessment of aspiration risk in acute ischaemic stroke-evaluation of the simple swallowing provocation test. Journal of Neurology Neurosurg Psychiatry 79: 312-314.

6. Bax L, McFarlane M, Green E, Miles A (2014) Speech-language pathologist-led fiberoptic endoscopic evaluation of swallowing: functional outcomes for patients after stroke. J Stroke Cerebrovasc Dis 23: e195-200. [Crossref]

7. Chong MS, Lieu PK, Sitoh YY, Meng YY, Leow LP (2003) Bedside clinical methods useful as screening test for aspiration in elderly patients with recent and previous strokes. Ann Acad Med Singapore 32: 790-794.[Crossref]

8. Daniels SK, McAdam CP, Brailey K, Foundas AL (1997) Clinical Assessment of Swallowing and Prediction of Dysphagia Severity. American Journal of SpeechLanguage Pathology 6: 17-24

9. DePippo KL, Holas MA, Reding MJ (1994) The Burke dysphagia screening test: validation of its use in patients with stroke. Archives of Physical Medicine and Rehabilitation 75: 1284-1286.

10. Kidd D, Lawson J, Nesbitt R, MacMahon J (1993) Aspiration in acute stroke: a clinical study with videofluoroscopy. Q J Med 86: 825-829.[Crossref]

11. Lim SH, Lieu PK, Phua SY, Seshadri R, Venketasubramanian N, et al. (2001) Accuracy of bedside clinical methods compared with fiberoptic endoscopic examination of swallowing (FEES) in determining the risk of aspiration in acute stroke patients. Dysphagia 16: 1-6.

12. Mann G, Hankey GJ (2001) Initial clinical and demographic predictors of swallowing impairment following acute stroke. Dysphagia 16: 208-215.[Crossref]

13. Nishiwaki K, Tsuji T, Liu M, Hase K, Tanaka N, et al. (2005) Identification of a simple screening tool for dysphagia in patients with stroke using factor analysis of multiple dysphagia variables. Journal of Rehabilitation Medicine 37: 247-251.

14. Somasundaram S, Henke C, Neumann-Haefelin T, Isenmann S, Hattingen E, et al (2014) Dysphagia risk assessment in acute left-hemispheric middle cerebral artery stroke. Cerebrovascular Diseases 37: 217-222.

15. Wilson RD, Howe EC (2012) A cost-effectiveness analysis of screening methods for dysphagia after stroke. PMR 4: 273-282. [Crossref]

16. Zhou Z, Salle J, Daviet J, Stuit A, Nguyen C (2011) Combined approach in bedside assessment of aspiration risk post stroke: PASS. Eur J PhysRehabil Med 47: 441-446. [Crossref]

17. Deeks, Macaskill, Irwig (2005) Functional outcomes for patients after stroke. Journal of Stroke and Cerebrovascular Diseases 23: e195-e200.

18. Osawa A, Maeshima S, Matsuda H, Tanahashi N (2013) Functional lesions in dysphagia due to acute stroke: discordance between abnormal findings of bedside swallowing assessment and aspiration on videofluorography. Neuroradiology 55: 413-421.

19. Osawa A, Maeshima S, Tanahashi N (2013) Water-swallowing test: screening for aspiration in stroke patients. Cerebrovasc Dis 35: 276-281.[Crossref]

20. Maeshima S, Osawa A, Miyazaki Y, Seki Y, Miura C, et al. (2011) Influence of dysphagia on short-term outcome in patients with acute stroke. Am J Phys Med Rehabil90: 316-320. [Crossref]

21. Tohara H, Saitoh E, Mays KA, Kuhlemeier K, Palmer JB (2003) Three tests for predicting aspiration without videofluorography. Dysphagia 18: 126-134.[Crossref]

22. Deeks JJ (2001) Systematic reviews in health care: Systematic reviews of evaluations of diagnostic and screening tests.BMJ 323: 157-162.[Crossref]

23. Liberati A, Altman DG, Tetzlaff J, Mulrow C, Gøtzsche PC, et al. (2009) The PRISMA statement for reporting systematic reviews and meta-analyses of studies that evaluate healthcare interventions: Explanation and elaboration. Annals of Internal Medicine 151: W-65.

24. Whiting PF, Rutjes AW, Westwood ME, Mallett S, Deeks JJ, et al. (2011) QUADAS-2: a revised tool for the quality assessment of diagnostic accuracy studies. Ann Intern Med 155: 529-536. [Crossref]

Copyright: (C2016 Chuang CH. This is an open-access article distributed under the terms of the Creative Commons Attribution License, which permits unrestricted use, distribution, and reproduction in any medium, provided the original author and source are credited. 